\title{
O DESAFIO DO GEORREFERENCIAMENTO DE CARTAS ANTIGAS EM ESCALA CADASTRAL EM APOIO À ESTRUTURAÇÃO DE UMA BASE DE DADOS GEOESPACIAIS - ESTUDO DE CASO PARA O MUNICÍPIO DO RIO DE JANEIRO
}

\author{
The challenge of georeferencing old maps on a cadastral scale in support of structuring a geospatial \\ database - a case study for the municipality of Rio de Janeiro
}

Carla Bernadete Madureira $\mathrm{Cruz}^{\mathrm{A}}$

(iD) Rafael Silva de Barros ${ }^{\mathbf{A}}$

Raphael Corrêa de Souza Coelho ${ }^{\text {B }}$

João Vitor Freitas Pereira Abrantes Marques ${ }^{\mathrm{A}}$

(D) Laiana Lopes do Nascimento ${ }^{\mathrm{C}}$

(iD) Maíra Silva Matos ${ }^{\mathbf{A}}$

(iD) Vandré Soares Viégas ${ }^{\text {A }}$

Elizabeth Maria Feitosa da Rocha de Souza ${ }^{\text {A }}$

(D) Gabriel do Santos Duarte ${ }^{\mathrm{A}}$

(D) Ícaro Azevedo da Silva ${ }^{\mathbf{B}}$

Janaina Valeska Raposo Viana ${ }^{{ }^{B}}$

(iD) Jéssica Carvalho Vianna $\mathrm{Co}^{\mathrm{B}}$

(iD) Daniel Junges Menezes ${ }^{\text {B }}$

Cárita da Silva Sampaio ${ }^{\text {B }}$

\author{
${ }^{\text {A }}$ Universidade Federal do Rio de Janeiro (UFRJ), Rio de Janeiro, RJ, Brasil \\ ${ }^{\text {B }}$ Secretaria de Coordenação e Governança do Patrimônio da União (SPU), Brasília, DF, País \\ ${ }^{\mathrm{C}}$ Universidade Federal Fluminense (UFF), Niterói, RJ, Brasil
}

Recebido em: 08/02/2021 | 27/10/2021～DOI: $10.12957 /$ tamoios.2021.56122

Correspondência para: Carla Bernadete Madureira Cruz (carlamad@gmail.com)

\begin{abstract}
Resumo
Com evolução tecnológica, a Cartografia apresentou mudanças tanto em nível de aquisição, como em nível de produção e disponibilização de dados. Muitas destas mudanças justificam a investigação de soluções metodológicas para a recuperação de mapas antigos. É o caso das informações referentes às áreas de patrimônio da União (Ministério do Planejamento, Desenvolvimento e Gestão), definidas de forma legal através de normativas, que representam documentos oficiais. O município do Rio de Janeiro, foco deste estudo, é considerado um exemplo de complexidade máxima em termos desta cartografia, apresentando características únicas. O objetivo deste trabalho está associado à proposição de soluções que visem o resgate de uma cartografia cadastral antiga, com status de documento legal, que precisa ser recuperada para atender às funcionalidades da gestão do patrimônio da União. A pesquisa propõe ainda, uma tipologia relacionada às condições originais das folhas, de modo a orientar o método de georreferenciamento a ser adotado e contribuir para a compreensão da qualidade destes produtos. Os resultados encontrados mostram que as folhas com referências cartográficas e grade de coordenadas mantiveram acurácia equivalente às suas escalas originais. As folhas sem essas informações passaram a ter exatidões compatíveis com o especificado para escalas menores, chegando até a escala 1:5.000.
\end{abstract}

Palavras-chave: georreferenciamento; documento; cadastral; exatidão; tipologia 
O desafio do georreferenciamento de cartas antigas em escala cadastral em apoio a estruturação de uma base de dados geoespaciais - estudo de caso para o município do Rio de Janeiro.

Cruz, C.B. M; Barros, R.S; Coelho, R.C.S; Marques, J.V, J.V F.P.A; Nascimento,

\begin{abstract}
With the technological evolution, Cartography has shown changes both in terms of the acquisition, as in the level of production and availability of data. Many of these changes justify the investigation of methodological solutions for the recovery of old maps. This is the case for information regarding the Union's heritage areas, legally defined through normative instructions, which represent official documents. The municipality of Rio de Janeiro, the focus of this study, is considered an example of maximum complexity in terms of this cartography, presenting unique characteristics. The objective of this paper is associated with the proposition of solutions aimed at the rescue of old cadastral cartography, with the status of a legal document, which needs to be recovered to meet the functionalities of the Union's heritage management. The research also proposes a typology related to the original conditions of the maps, to guide the georeferencing method to be adopted and contribute to the understanding of their final quality. The results show that the sheets with cartographic references and coordinate grid maintained accuracy equivalent to their original scales. The sheets without this information showed accuracy compatible with the pattern specified for smaller scales, reaching scale 1: 5,000.
\end{abstract}

Keywords: georeferencing; document; cadastral; accuracy; typology

\title{
INTRODUÇÃO
}

Sempre foi relevante a representação da realidade por meio de formas que atendam às necessidades relativas à compreensão espacial e à medição de objetos e/ou fenômenos. Essas representações acabam por se configurar em instrumentos de interpretação por estarem associadas a formas particulares de leitura e de transposição de conhecimentos associados a um determinado momento histórico (Menezes e Fernandes, 2013). Não é à toa que mudam com o tempo, necessitando de constantes atualizações.

A humanidade constituiu sua história por meio dessas leituras ou linguagens. Se fizermos uma viagem no tempo observando as formas de representação do mundo, é possível reconhecer que esses quadros inicialmente estiveram associados exclusivamente a mapas e, apenas mais recentemente, incluíram um amplo espectro de imagens verticais - terrestres, aéreas ou orbitais (Gomes, 2017). Assim, tanto a cartografia quanto o sensoriamento remoto são considerados, por excelência, importantes formas de representação espacial, atendendo a demandas interpretativas e de mensuração.

Dados espaciais envolvem um conjunto amplo de informações geométricas que podem ou não estar relacionadas a um georreferenciamento no sentido clássico do termo, com coordenadas associadas a um sistema de referência terrestre. Dentre essa ampla família, os mapas são, sem dúvida, a expressão máxima da representação espacial de objetos e fenômenos, sejam estes de origem natural ou antrópica. Por outro lado, a cartografia se configura em uma área muito antiga, que acompanha nossa evolução como civilização desde os seus primórdios, quando nos encontrávamos no ponto do não saber (Castiglione, 2009) e, desde então, vem sofrendo transformações conceituais e tecnológicas crescentes. 
De acordo com Figueiredo (2008), o termo "documento cartográfico" é muito usado para expressar produtos cartográficos em geral, ressaltando-se que o sentido da palavra documento evoluiu para o mesmo sentido da palavra "prova" e, assim, a partir do século XIX, esses produtos acabaram por receber o reconhecimento de testemunhos históricos das formas/limites e da localização espaço-temporal de elementos da superfície terrestre (Le Goff, 1996). Pode-se afirmar, portanto, que o mapa é um documento que define uma representação espacial seletiva de um fato ou, ainda, que uma representação quando definida como documento cartográfico tem funcionalidade de prova, podendo ser tratada como uma referência do original.

Os principais elementos que constam de um documento cartográfico podem variar no tempo. Assim, é comum que os elementos de referência cartográfica (sistemas geodésicos e de coordenadas, por exemplo), sejam diferentes quando comparamos bases antigas com as atuais, sem considerar a possibilidade - não tão rara - de que estas informações não estejam explícitas nos documentos mais antigos. Tais condições geram dificuldades para uma integração segura de mapas de diferentes períodos, sendo mais grave para o caso da cartografia em escala cadastral.

A Cartografia, como outras áreas do conhecimento, apresentou significativas mudanças tanto em nível de aquisição, como em nível de produção e disponibilização de dados ao longo do tempo, fruto de uma evolução tecnológica que tem se intensificado cada vez mais (Menezes e Fernandes, 2013). Muitas destas mudanças justificam a investigação de soluções metodológicas que viabilizem a recuperação de mapas antigos como um dado espacial que possa ser integrado com dados referentes a períodos mais recentes, outras escalas e novas iniciativas.

No início dos anos 90, o Brasil se encontrava debruçado pelo imenso esforço de converter dados analógicos em digitais. Já se passaram 30 anos e este esforço, apesar de ter reduzido, ainda apresenta desafios complexos para o tratamento de determinados conjuntos de dados que necessitam de leituras cuidadosas e de soluções que fogem ao convencional. Isso se explica pelo complexo volume de dados históricos acumulado e pela falta, muitas vezes, de informações relativas aos métodos e às referências cartográficas adotados no momento de sua elaboração.

Seria fácil dizer "melhor começar de novo", mas nem sempre isto é possível! Para determinadas aplicações, dados associados a referências históricas são fundamentais para se entender os processos que nos levaram até o presente e por carregarem informações que precisam ser recuperadas, as vezes em um contexto ancorado no rigor da lei. É o caso das informações referentes às áreas de patrimônio da união, definidas de forma legal através de instruções normativas. Deve-se ter cuidado ainda com os reflexos relacionados à exatidão destes dados, muitas vezes desconhecida, por se tratar de registros oficiais, cuja qualidade é determinante para a tomada de decisão em diferentes aspectos. 
Para o caso das faixas de terrenos de marinha relacionadas às zonas costeiras, por exemplo, tem-se ainda a necessidade de se resgatar o traçado de suas linhas definidoras (Linha de Terreno de Marinha ou LTM e Linha de Preamar ou LPM) (Thiers, 2012). A complexidade desta tarefa passa, normalmente, pela recuperação de uma cartografia antiga, analógica, em escala cadastral, que muitas vezes carece de informações espaciais relativas ao georreferenciamento de suas folhas e que não apresenta muita correlação com os elementos observados no momento presente, seja ao se observar a cartografia vigente ou através de visitas a campo.

Para complicar, não é possível abstrair a diversidade de iniciativas encontrada em um país de vastas dimensões como o Brasil. Assim, esta complexidade é bastante diferenciada quando analisamos os recortes regionais do país, onde áreas mais antigas e com uma historicidade de ocupação diversa podem apresentar particularidades que vão requerer cuidados especiais, longe das soluções metodológicas tradicionais.

O município do Rio de Janeiro, foco do presente estudo, é considerado um exemplo de complexidade máxima em termos desta cartografia voltada à representação do patrimônio da União, apresentando características únicas quando comparado às outras áreas no país. Isto se justifica, prioritariamente, por duas razões: (i) pelo fato de sua produção cartográfica cadastral apresentando os elementos definidores das áreas de interesse ser muito antiga, tendo sido criada em um contexto de tecnologias ultrapassadas ou mal documentadas, ou ainda com a ausência de informações cartográficas fundamentais; e (ii) pela cidade do Rio de Janeiro ter sido capital do Brasil e apresentar uma complexa rede de ocupação envolvendo o patrimônio público federal tendo, desta forma, significativas áreas prioritárias que não podem ser ignoradas.

Esta complexidade exige soluções diferenciadas do tradicional, que buscam incorporar o máximo desta cartografia numa base digital estruturada que possa apoiar as demandas de gestão do patrimônio da União numa área de grande importância. $\mathrm{O}$ esforço de recuperação envolve muitos desafios, sendo o georreferenciamento somente o primeiro passo para se alcançar a estruturação de uma base cartográfica padronizada, que possa se integrar a dados mais recentes e que atenda às funcionalidades previstas.

O objetivo do presente trabalho está associado à proposição de soluções metodológicas que visem o resgate de uma cartografia cadastral antiga, com status de documento legal, que precisa ser recuperada para atender às demandas da gestão do patrimônio da União, tendo como estudo de caso o município do Rio de Janeiro. Neste sentido, propõe-se ainda uma tipologia relacionada às condições originais das folhas do acervo cartográfico trabalhado, de modo a orientar o método de georreferenciamento a ser adotado e contribuir, em um segundo momento, para a compreensão da qualidade do posicionamento final destes produtos, embasando assim a sua utilização. 
Apesar da etapa de recuperação do georreferenciamento de uma cartografia antiga não representar toda a complexidade que envolve a elaboração de uma base cartográfica vetorial, estruturada e representativa, não há dúvidas de que que os reflexos em termos da geometria e exatidão planimétrica de seus elementos são profundamente dependentes dos resultados desta fase. Ressalta-se ainda que é fundamental conhecer e registrar esta condição final de modo a dar suporte aos cálculos e decisões a serem efetuados sobre ela.

\section{Caracterização da cartografia do município do Rio de Janeiro no contexto do patrimônio da União}

A cartografia representativa do patrimônio da União cobre parte do território brasileiro e é estruturada regionalmente, sendo o estado do Rio de Janeiro uma área importante neste contexto. A distribuição desta cartografia é articulada através de coleções, normalmente associadas a uma determinada escala e data. Cada coleção é composta por um conjunto de folhas variado e possui representatividade espacial que não segue um padrão determinado.

O estado do Rio de Janeiro apresenta uma distribuição composta por 107 coleções, englobando um total de 3.104 folhas, variando nas escalas cadastrais de 1:500 a 1:5.000, com levantamentos realizados no período temporal entre os anos 1930 e 2010 . Aproximadamente $37 \%$ desta cartografia, 1.143 folhas, já se encontrava em meio digital, vetorial e georreferenciado, em formato CAD; mas os 63\% restantes (1.961 folhas), com forte representatividade no município do Rio de Janeiro, se encontrava em formato analógico.

A Figura 1 apresenta a distribuição desta cartografia para o estado do Rio de Janeiro, ressaltando a proporção, por data, da cobertura do município do Rio de Janeiro. É possível perceber que o período mais significativo de mapeamento do município está entre a década de 30 e 70, tendo-se ainda uma certa representatividade nos anos 90.

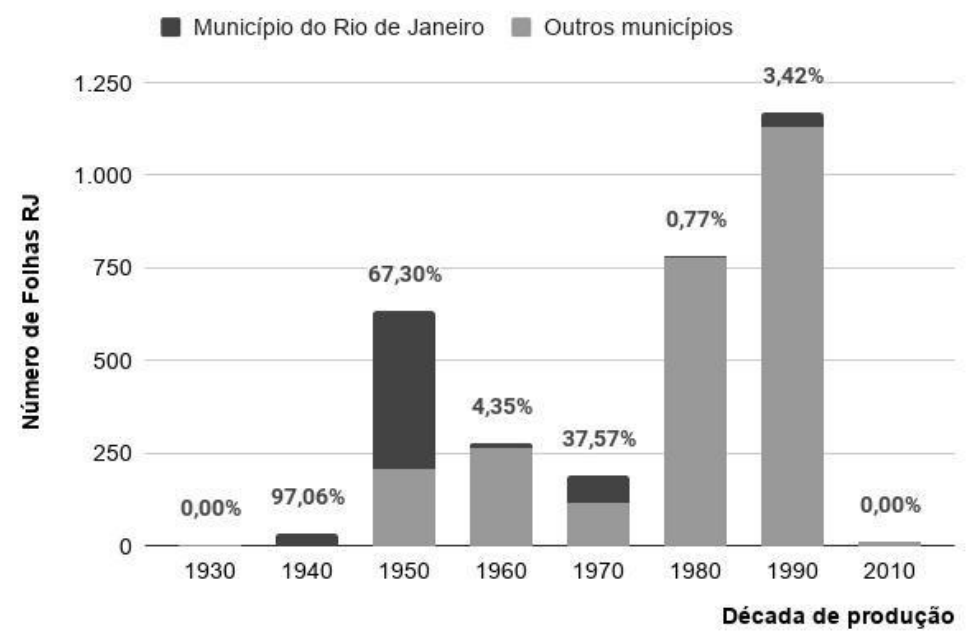


Figura 1 - Distribuição da cartografia do patrimônio da União para o estado e município do Rio de Janeiro, considerando os períodos de levantamento.

Esta cartografia tem a particularidade de registrar, além das propriedades consideradas relevantes na data do levantamento, através de loteamentos, áreas construídas e arruamentos, as linhas definidoras dos terrenos da união, a LPM (Linha de Preamar) e a LTM (Linha de Terreno de Marinha), sendo estas linhas os principais alvos de resgate, dada a dificuldade de uma nova delimitação geodésica de seu traçado.

A origem dos terrenos de marinha e seus acrescidos remonta à época do Brasil Colonial, e sua finalidade era "assegurar às populações e à defesa nacional o livre acesso ao mar e às áreas litorâneas". Esses terrenos são medidos a partir da linha do preamar médio de 1831 (LPM) até 33 metros para o continente ou para o interior das ilhas costeiras com sede de município, o que definiria a linha limite do terreno de marinha (LTM). Considerando este princípio, as parcelas imobiliárias localizadas na faixa entre as duas linhas são consideradas bens dominiais ou dominicais da União e seu domínio útil é concedido sob a forma de enfiteuse.

Considerando o estudo de caso do município do Rio de Janeiro, esta cartografia é caracterizada por ser totalmente analógica e composta por 590 folhas, organizadas em 46 coleções. As escalas de representação variam entre 1:500 e 1:2.000, totalmente inseridas no universo cadastral.

A Figura 2 apresenta a distribuição da cartografia para o estado e município do Rio de Janeiro, considerando as escalas de representação. Os valores percentuais indicam o quanto a cartografia do município é representativa em cada escala quando comparada ao estado do Rio de Janeiro.

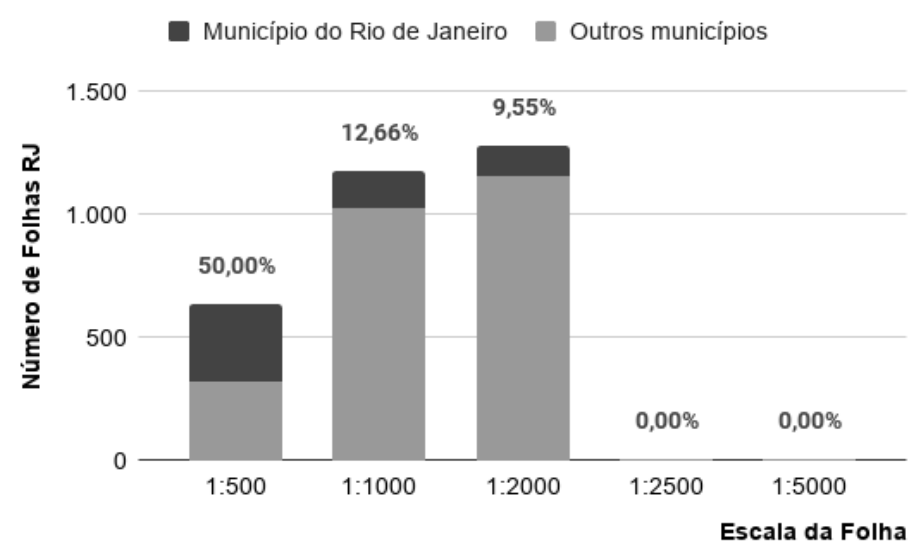

Figura 2: Distribuição da cartografia do patrimônio da União para o estado e município do Rio de Janeiro, considerando as escalas de mapeamento. 
Dada a relevância e complexidade do município do Rio de Janeiro, o foco deste artigo é apresentar uma proposta metodológica de recuperação do georreferenciamento de uma cartografia antiga e analógica, e que representa o principal volume de terrenos de marinha no contexto regional e até nacional, analisando a qualidade dos resultados obtidos até o momento.

O município do Rio de Janeiro é, atualmente, a capital do estado e principal município da segunda maior Região Metropolitana brasileira. Com apenas $1.255 \mathrm{~km} 2$ de área total, apresenta importância histórica tendo sido sucessivamente capital da colônia portuguesa do Estado do Brasil (1763-1815), do Reino Unido de Portugal, Brasil e Algarves (1815-1822), do Império do Brasil (1822-1889) e da República dos Estados Unidos do Brasil até 1960, quando a sede do governo foi transferida para a recém-construída Brasília. Todo este histórico per si, explica a complexidade das áreas de patrimônio da União concentradas em seu território.

A Figura 3 traz o mapa de localização do município, ressaltando seu contexto regional.

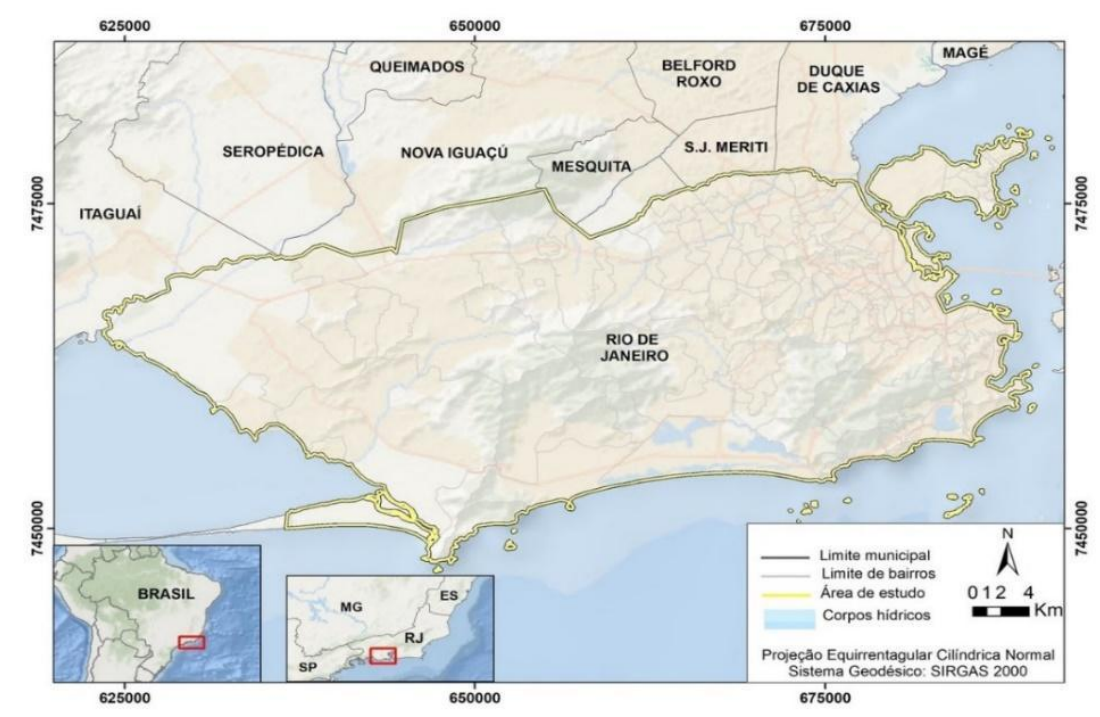

Figura 3: Mapa de localização do município do Rio de Janeiro.

As Figuras 4 e 5 apresentam a distribuição espacial das 590 folhas de acordo com as datas de levantamento e escalas de mapeamento, respectivamente. A leitura da distribuição das datas mostra que a cartografia mais antiga (da década de 40) está concentrada na zona sul do município, enquanto a cartografia realizada nos anos 50 apresenta ampla distribuição. Também será na zona sul, e parte da zona norte, que encontraremos as maiores escalas de mapeamento (1:500). 


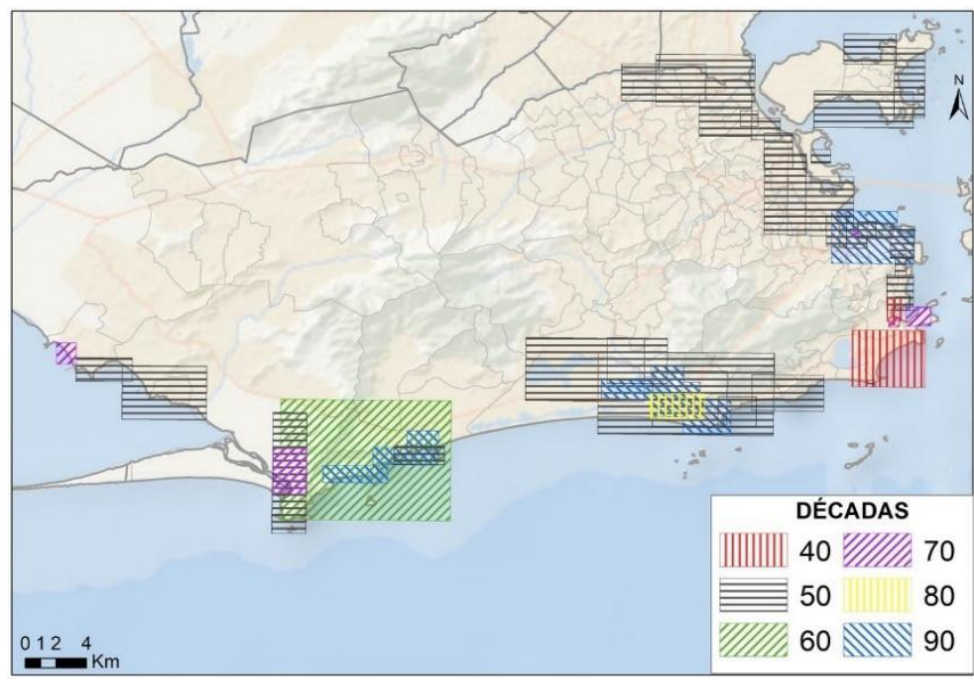

Figura 4: Distribuição espacial da cartografia do município do Rio de Janeiro por data de levantamento.

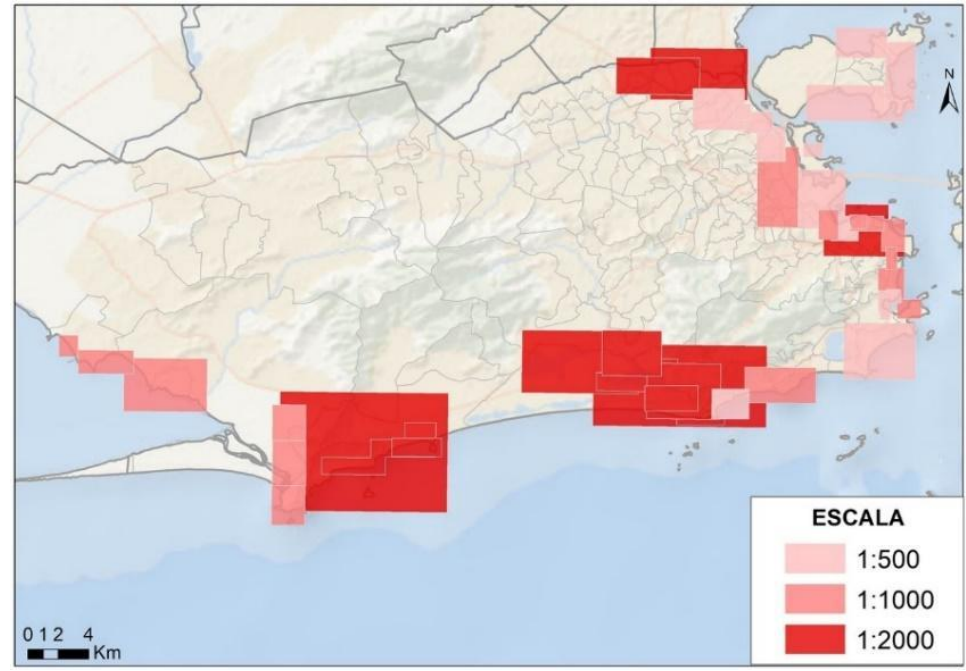

Figura 5: Distribuição espacial da cartografia do município do Rio de Janeiro por escala.

Proposta metodológica para georreferenciamento.

PROPOSTA METODOLÓGICA PARA GEORREFERENCIAMENTO DE FOLHAS ANTIGAS

O desafio do georreferenciamento desta cartografia originalmente analógica teve início com uma proposta de classificação em relação às condições originais destas folhas, que deu origem a uma tipologia definida por 3 classes, a saber:

- TIPO 1: folhas com referências cartográficas e grid de coordenadas. 
- TIPO 2: folhas sem referências cartográficas e grid de coordenadas, mas com elementos com maior potencial de georreferenciamento, como uma maior densidade de áreas construídas e arruamentos com associação a elementos recentes. Também foi considerada a clareza de definição das linhas LTM e LPM.

- TIPO 3: folhas sem referências cartográficas e grid de coordenadas e, ainda, com poucos elementos com potencial de georreferenciamento.

As Figuras 6, 7 e 8 apresentam exemplos de folhas classificadas como dos TIPOS 1, 2 e 3 , respectivamente.

O gráfico apresentado na Figura 9 mostra a distribuição das folhas de acordo com esta tipologia, para o caso do estado do Rio de Janeiro, com especial atenção para o município do Rio de Janeiro. É possível verificar que no município do Rio de Janeiro não se tem bases em formato vetorial e que quase $56 \%$ das folhas que apresentam as condições mais difíceis para recuperação do georreferenciamento (TIPO 3), se localizam em seu território; e mais, que o município possui apenas $6 \%$ das folhas que apresentam as informações cartográficas necessárias para um georreferenciamento clássico (TIPO 1).

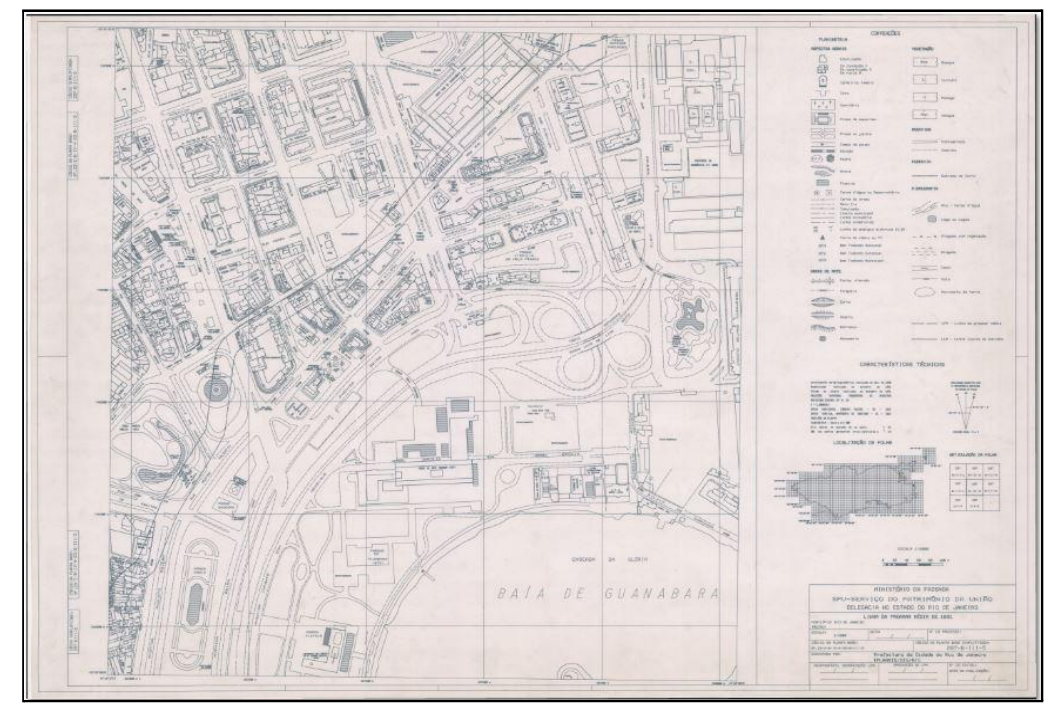

Figura 6: Exemplo de folha do acervo classificada como do TIPO 1. 
O desafio do georreferenciamento de cartas antigas em escala cadastral em apoio a estruturação de uma base de dados geoespaciais - estudo de caso para o município do Rio de Janeiro.

Cruz, C.B. M; Barros, R.S; Coelho, R.C.S; Marques, J.V, J.V F.P.A; Nascimento,

L.L;

Matos, M.S; Viégas, V.S; Souza, E.M.F.R; Duarte, G.S; Silva, I.A; Viana, J.V.R; Co, J.C.V; Menezes, D.J. \& Sampaio, C.S.

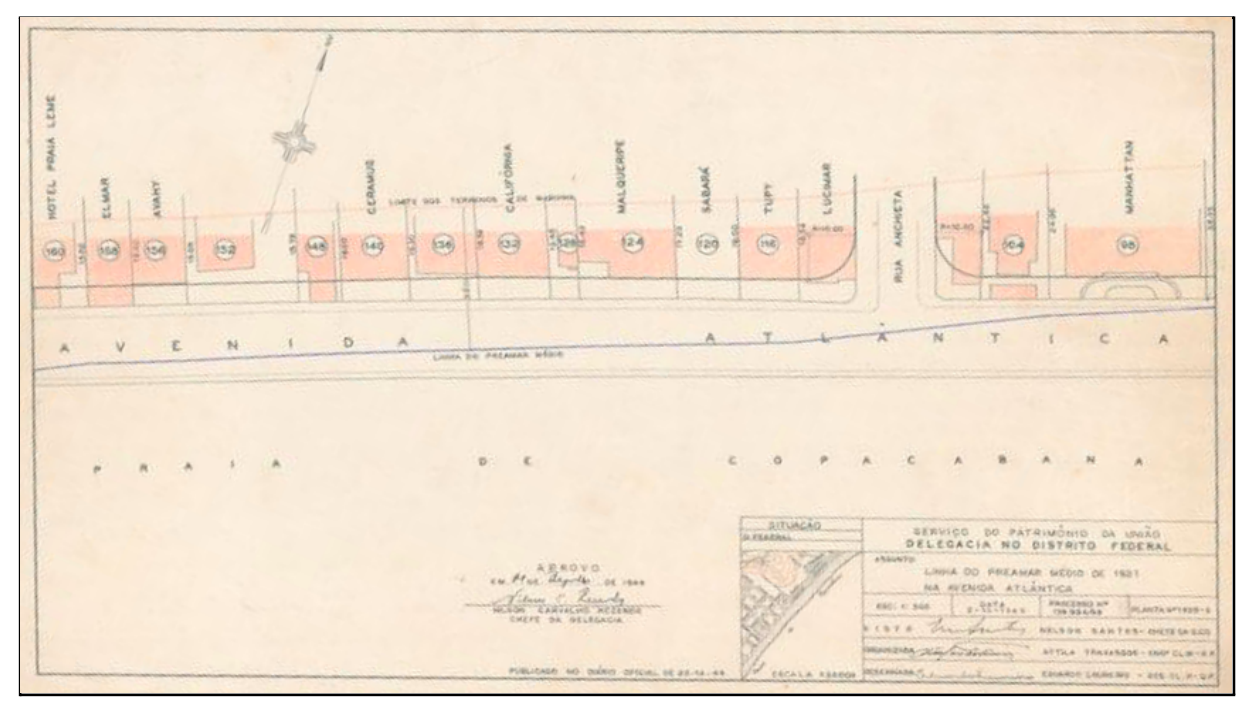

Figura 7: Exemplo de folha do acervo classificada como do TIPO 2.

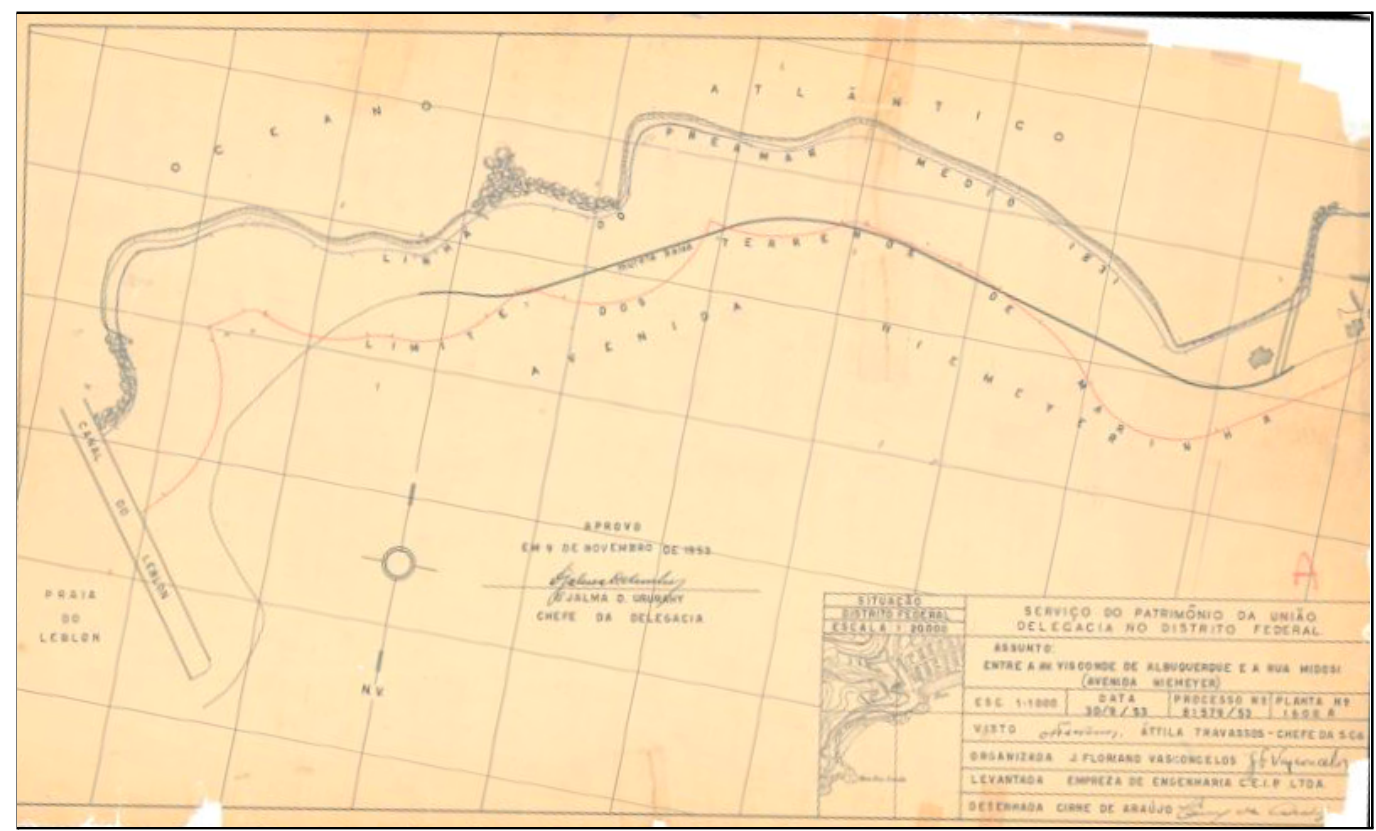

Figura 8: Exemplo de folha do acervo classificada como do TIPO 3. 


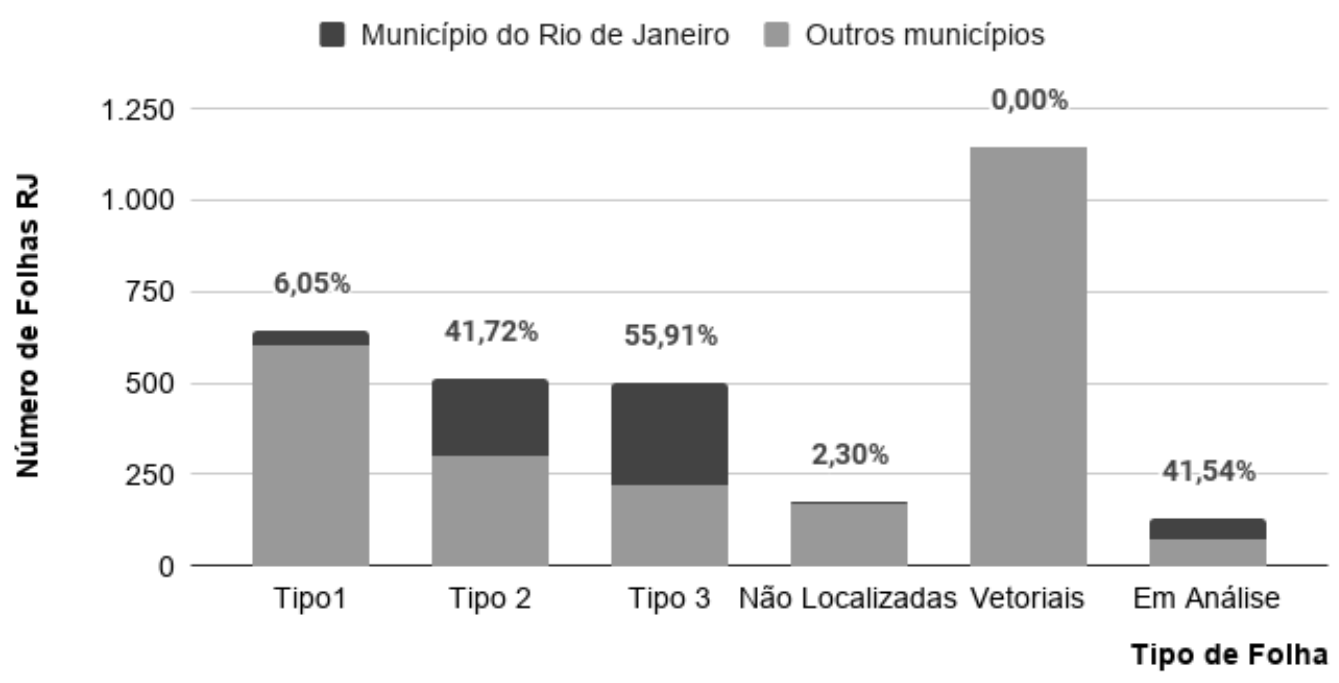

Figura 9: Distribuição comparativa da cartografia do município e do estado do Rio de Janeiro considerando a tipologia proposta. Os maiores percentuais dos tipos 2 e 3 mostram a complexidade da cartografia do município.

A Figura 10 apresenta a distribuição das folhas no município de acordo com a tipologia. Pode-se perceber que esta cartografia classificada como do TIPO 1 se concentra em 3 núcleos: o centro da cidade, São Conrado e arredores e Recreio dos Bandeirantes. Observa-se ainda que os $2,3 \%$ das folhas que ainda não foram localizadas fisicamente e que fazem parte do município, estariam concentradas na AP4 (Área de Planejamento 4), referente a parte da Zona Oeste que abrange Barra da Tijuca, Recreio dos Bandeirantes e Jacarepaguá. 


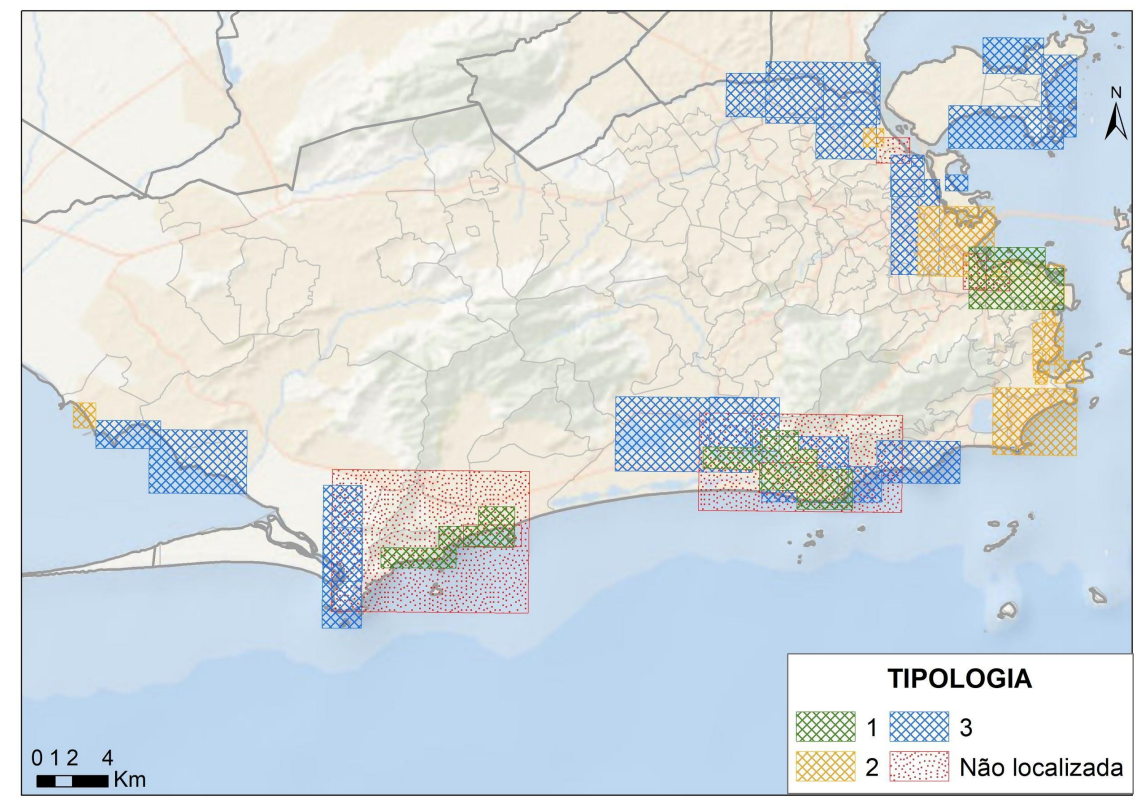

Figura 10: Distribuição espacial da cartografia do município do Rio de Janeiro por tipos.

A proposta definida para o georreferenciamento desta cartografia, considerou: (i) a necessidade de independência da escala de mapeamento; (ii) privilegiar o tempo de execução de todo o processo, dado o tamanho do acervo para o estado e país; (iii) a necessidade de estabelecer tolerâncias viáveis e que refletissem, ao mesmo tempo, a qualidade do processo.

Considerando a tipologia proposta, foram definidos caminhos metodológicos distintos para o georreferenciamento e avaliação das folhas. Para o caso do georreferenciamento, os procedimentos adotados para a cartografia dos TIPOS 1 e 2 são apresentados nas Figuras 11 e 12, respectivamente. As especificidades que diferenciam cada caso, variam com: (i) a natureza dos pontos utilizados como de controle e checagem; (ii) a quantidade de pontos adotada; (iii) a distribuição dos pontos em relação à área mapeada na folha; (iv) as tolerâncias estabelecidas. Estas variações tiveram que ser ajustadas para cada tipo diagnosticado, partindo-se da hipótese de que a classificação da condição original influencia os resultados.

Para as 39 folhas do TIPO 1, utilizou-se o próprio grid de coordenadas como referência para obtenção dos pontos. Pelo fato de o grid abranger a folha de maneira uniforme e em sua integridade, foi possível definir um total de 9 pontos distribuídos de forma bem abrangente. Também não foi necessário ter uma fonte de referência externa para obtenção das coordenadas, e nem se sofreu com a influência relativa a questões de variação de data e escala. As tolerâncias estabelecidas para esse processo fazem parte desta proposta e são apresentadas nos resultados. 
De modo a atender a falta de referências cartográficas dos demais tipos, foram necessários ajustes importantes no procedimento proposto. Para o caso das 79 folhas prioritárias dos TIPOS 2 e 3 a fonte de pontos usados para georreferenciamento e validação teve que ser externa e a quantidade e distribuição dos pontos ficou condicionada à existência de opções relacionáveis entre a folha antiga e a referência recente, o que não é trivial dado o grande intervalo temporal. Com as dificuldades de acesso às bases cadastrais das áreas de interesse, solicitou-se ao IPP (Instituto Pereira Passos, da Prefeitura do Rio de Janeiro) as ortofotos atuais na escala 1:2.000. Desta forma, as ortofotos foram utilizadas como referência cartográfica para obtenção de coordenadas de pontos identificáveis nos dois processos, o de georreferenciamento e o de avaliação. Os pontos selecionados foram definidos priorizando-se quinas de prédios, esquinas de ruas e quaisquer outras feições que fossem bem identificáveis nos dois produtos. Problemas referentes à paralaxe e às diferenças de datas tiverem que ser ponderados constantemente. Observou-se ainda um critério importante para esta seleção, que foi a condição primária de que os pontos não estivessem alinhados e, sempre que possível, fossem distribuídos em ambos os lados das LTM e LPM, foco principal da recuperação do processo de georreferenciamento.

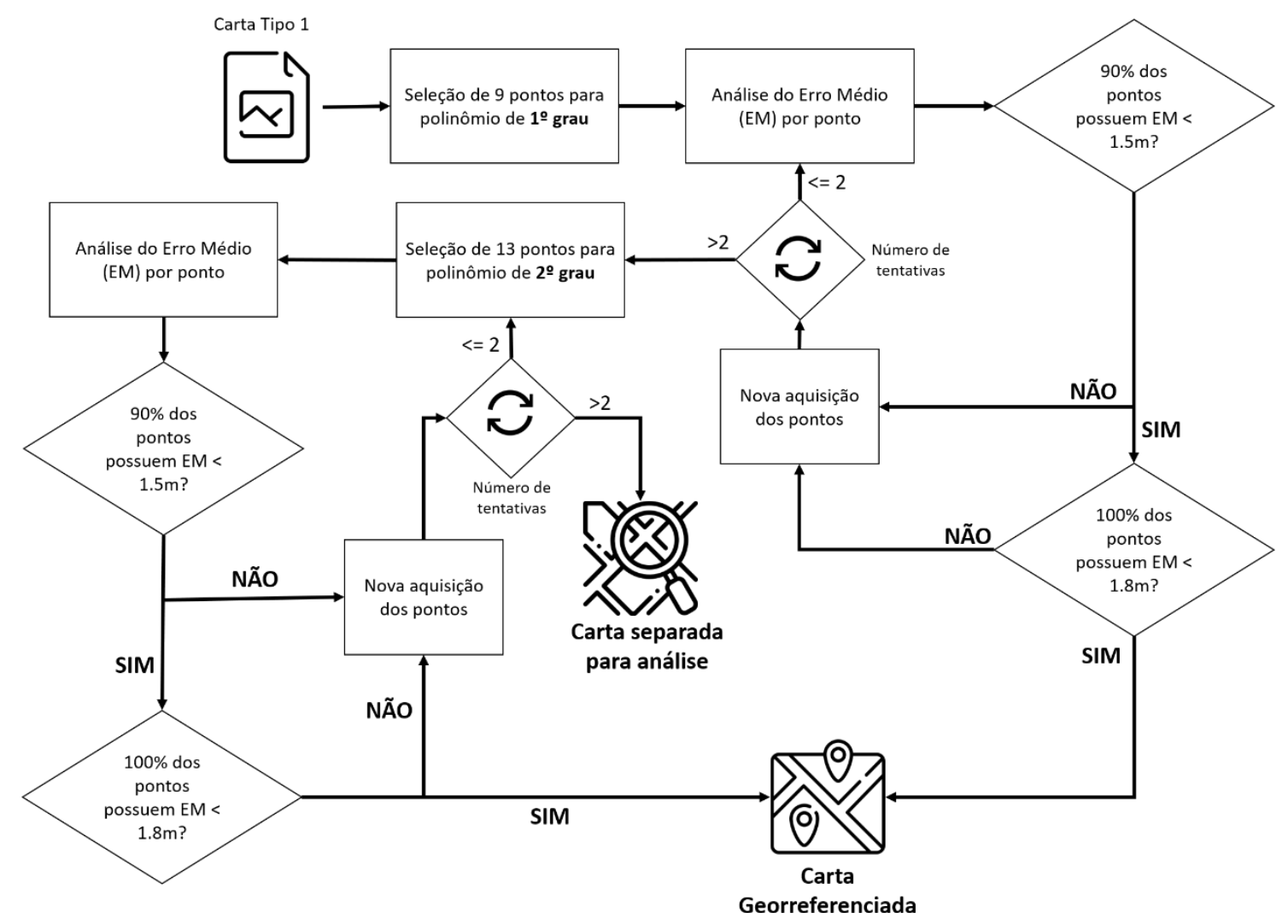


Figura 11: Processo de georreferenciamento das folhas classificadas como do TIPO 1.

A Figura 13 apresenta o procedimento proposto para a avaliação dos produtos georreferenciados, cuja estrutura não depende da tipologia das folhas. A única diferença é a natureza dos pontos adotados para checagem, que para o TIPO 1 foi o próprio grid de coordenadas, enquanto para o TIPO 2 (assim como para o TIPO 3) foram usadas as feições identificáveis tanto na cartografia antiga, como na ortofoto. Em ambos os casos, mantendo-se o cuidado de selecionar pontos distintos aos adotados no georreferenciamento.

Como a quantidade de folhas georreferenciadas do TIPO 3 foi pequena, com apenas 10 unidades, e estas folhas apresentavam características diferentes quanto aos elementos disponíveis para seleção de pontos, optou-se por tratar este tipo, no âmbito do presente artigo, como um experimento através da replicação do mesmo princípio usado para as folhas do TIPO 2.

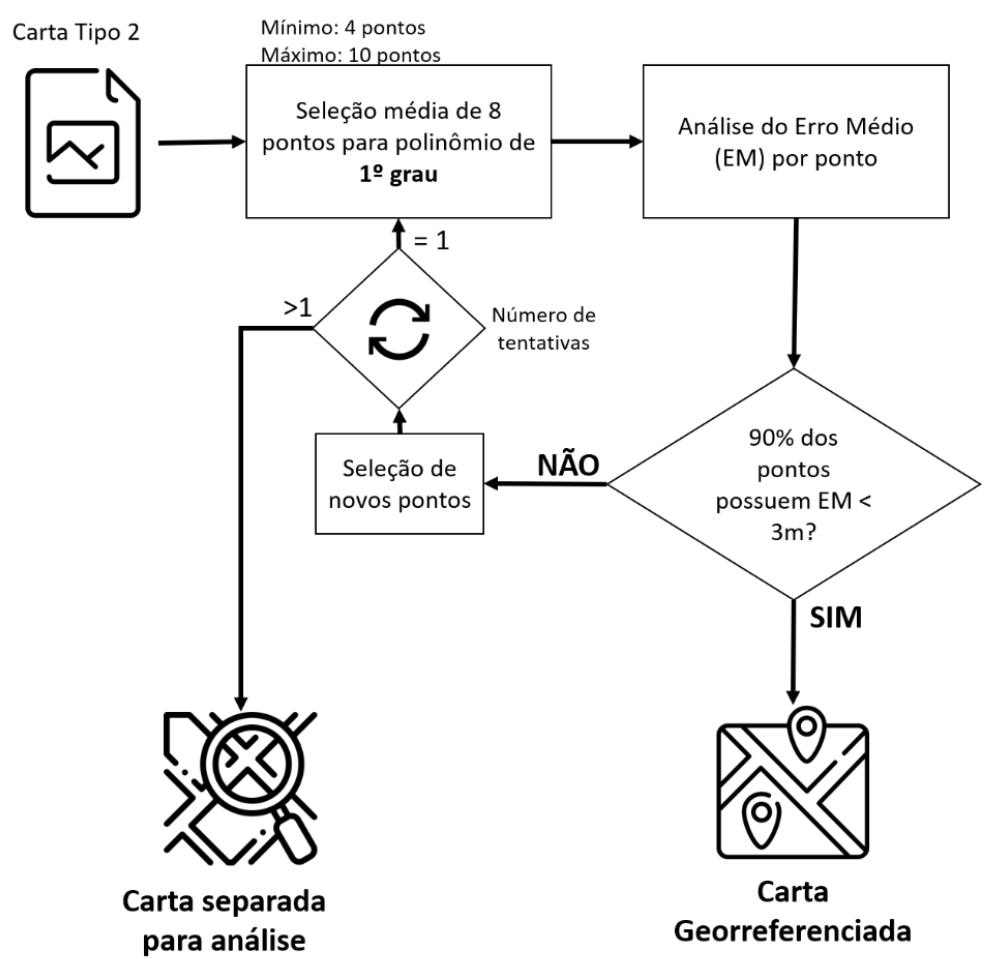

Figura 12: Processo de georreferenciamento das folhas classificadas como do TIPO 2. 


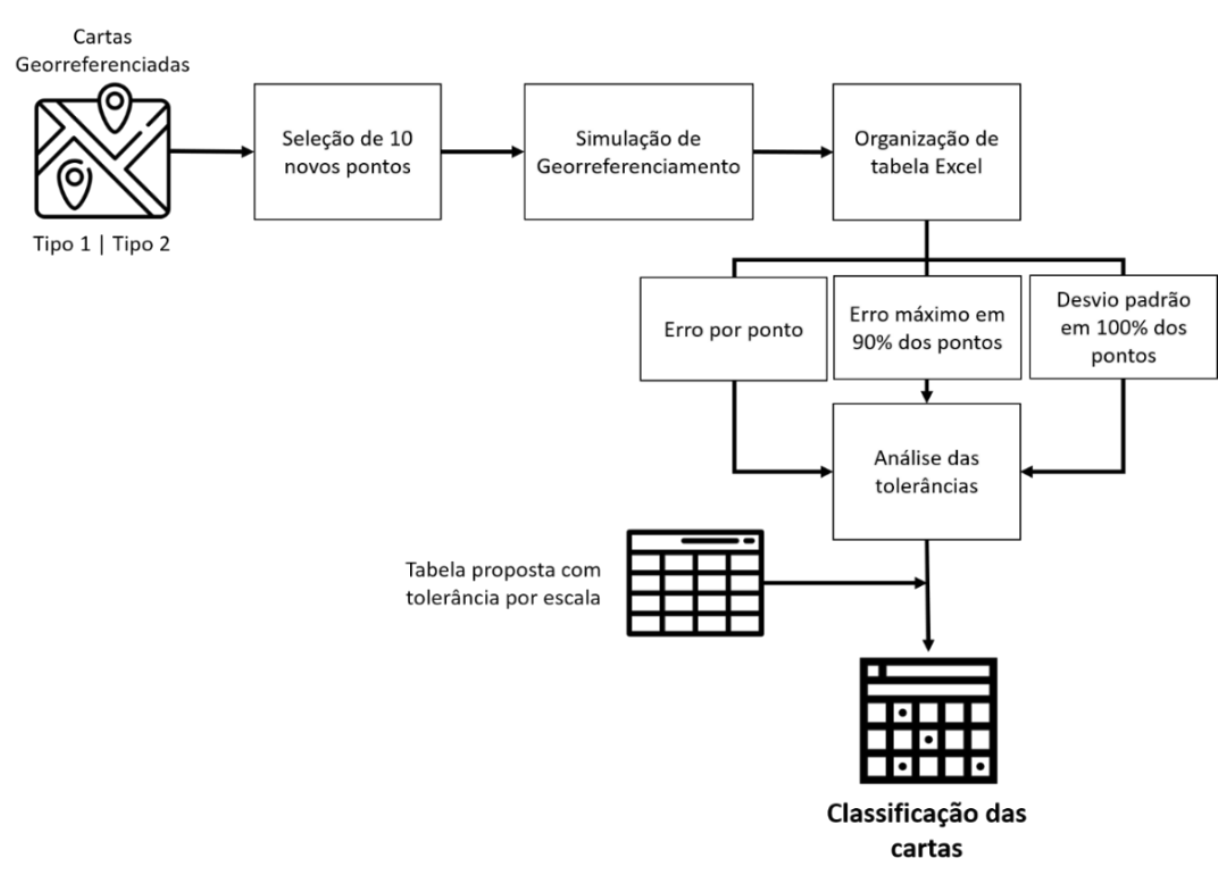

Figura 13: Processo de avaliação da qualidade do georreferenciamento das folhas classificadas como do TIPO 1 e TIPO 2.

Os dois procedimentos, apresentados nas Figuras 11 e 13 para o TIPO 1, foram incluídos no documento de referência "Metodologia de Conversão de Dados Geoespaciais da SPU (Capítulo Georreferenciamento)", (Ministério do Planejamento, 2018), servindo de orientação metodológica em nível nacional, devendo agora ser atualizados.

De modo a avaliar a qualidade final dos resultados obtidos, foi realizado um novo procedimento utilizando como referência a base cartográfica vetorial atual (escala 1:2.000), obtida junto ao IPP somente ao final dos procedimentos realizados. Dado a maior facilidade de obtenção de pontos identificáveis pela ortogonalidade do produto base e presença de elementos não visíveis nas fotografias, considerou-se relevante a repetição do processo para parte das folhas georreferenciadas dos TIPOS 1 e 2. A Figura 14 apresenta, de forma esquemática, as principais etapas desta nova avaliação. 


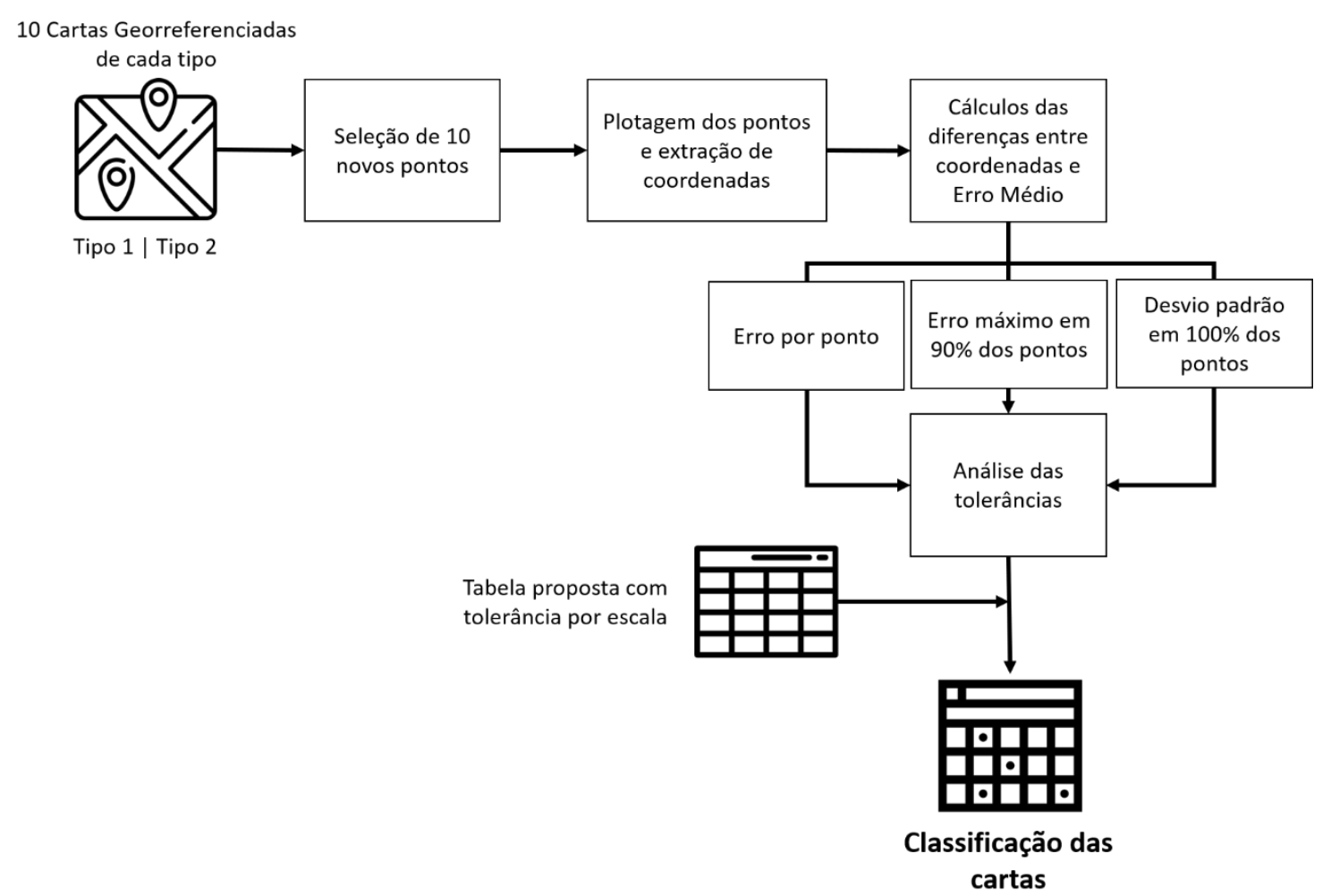

Figura 14: Novo processo de avaliação amostral da qualidade do georreferenciamento das folhas classificadas como do TIPO 1 e TIPO 2, utilizando a base vetorial da Prefeitura do Rio de Janeiro.

Considerando o volume e complexidade dos dados, estruturou-se ainda um banco de dados com interface interativa, modelada através do POWER BI, para facilitar as consultas e análises dos dados.

\section{ANÁLISE DOS RESULTADOS PRELIMINARES}

Como a proposta metodológica variou em função da tipologia definida para classificação das folhas a serem recuperadas, os resultados obtidos serão discutidos segundo a mesma lógica, priorizando os TIPOS 1 e 2, com uma apresentação dos resultados obtidos em caráter preliminar sobre o TIPO 3.

O princípio básico seguido preconiza que o valor de tolerância a ser usado como referência não pode ser mais rigoroso do que o esperado para o produto cartográfico original em meio analógico - que está sendo georreferenciado, em sua versão digital. Considerando este pressuposto, foi elaborado o quadro a seguir, com valores de acordo com o Padrão de Exatidão Cartográfica - PEC (Brasil, 1984), PEC/PCD (PEC/Produto Cartográfico Digital), acrescidos de uma maior tolerância sugerida para cada escala, para fins desta aplicação, a qual 
foi denominada Tolerância SPU. Os valores de tolerância foram escolhidos em função do tipo de produto que está sendo georreferenciado, bem como de suas características originais.

A Tabela 1 apresenta as tolerâncias propostas para a cartografia do patrimônio da União de acordo com a escala de mapeamento.

Tabela 1: Proposta de tolerâncias para o georreferenciamento das folhas classificadas.

\begin{tabular}{c|c|c|c|c|c|c|c|c|c|c|c|c}
\multicolumn{3}{c}{ Abordagens } & \multicolumn{2}{c|}{$1: 500$} & \multicolumn{2}{c|}{$1: 1.000$} & \multicolumn{2}{c|}{$1: 2.000$} & \multicolumn{2}{c}{$1: 5.000$} & \multicolumn{2}{c}{$1: 10.000$} \\
\hline Escalas & $\begin{array}{l}\text { PEC } \\
\text { PCD }\end{array}$ & SPU & Tol & DP & Tol & DP & Tol & DP & Tol & DP & Tol & DP \\
\hline & A & - & 0,14 & 0,09 & 0,28 & 0,17 & 0,56 & 0,34 & 1,40 & 0,85 & 2,80 & 1,70 \\
\hline A & B & 1 & 0,25 & 0,15 & 0,50 & 0,30 & 1,00 & 0,60 & 2,50 & 1,50 & 5,00 & 3,00 \\
\hline B & C & 2 & 0,40 & 0,25 & 0,80 & 0,50 & 1,60 & 1,00 & 4,00 & 2,50 & 8,00 & 5,00 \\
\hline C & D & 3 & 0,50 & 0,30 & 1,00 & 0,60 & 2,00 & 1,20 & 5,00 & 3,00 & 10,0 & 6,00 \\
\hline & & 4 & 1,00 & 0,60 & 2,00 & 1,20 & 4,00 & 2,40 & 10,0 & 6,00 & 20,0 & 12,0 \\
\hline & & 5 & 2,00 & 1,20 & 4,00 & 2,40 & 8,00 & 4,80 & 20,0 & 12,0 & 40,0 & 24,0 \\
& & & & & & & & & & & &
\end{tabular}

Como o procedimento proposto se baseia na avaliação do erro médio (EM), caso a tolerância não fosse atendida na primeira rodada, de acordo com os valores previstos na Tabela 1, o georreferenciamento deveria ser refeito refinando-se a seleção dos pontos de controle. Após novo processamento, caso o EM continuasse ultrapassando a tolerância estabelecida, o georreferenciamento poderia ser refeito com uma quantidade maior de pontos de controle, adotando-se um polinômio do $2^{\circ}$ grau. Se a tolerância ainda assim não fosse atendida, o georreferenciamento não deveria ser refeito, devendo essa situação ser registrada. Todas as 645 folhas do TIPO 1 que cobrem o estado do Rio de Janeiro tiveram seus resultados atendidos pelas tolerâncias propostas conforme a Tabela 1, apresentando-se superior ao esperado.

Apesar do foco deste artigo ser na cartografia do município do Rio de Janeiro, são apresentados resultados considerando todo o estado, no caso do TIPO 1, para mostrar a 
coerência e robustez dos mesmos, visto que o total de folhas avaliado é bem maior. Das 645 folhas do TIPO 1 em todo o estado do Rio de Janeiro, 606 se encontram na escala 1:1.000, enquanto as 39 folhas do município do Rio de Janeiro estão na escala 1:2.000. Ao analisar o conjunto total de folhas obteve-se os valores apresentados na Tabela 2. Pode-se observar que a média e o desvio padrão encontrados são muito baixos e o maior Erro Médio observado foi menor que 1 metro.

Tabela 2: Valores de média, desvio padrão, valores mínimo e máximo observados para os Erros Médios (EM) do georreferenciamento e da avaliação para todas as folhas do TIPO 1.

\begin{tabular}{l|c|c} 
Estatística & $\begin{array}{c}\text { Erro Médio } \\
\text { Georreferenciamento } \\
\text { (em metros) }\end{array}$ & $\begin{array}{c}\text { Erro Médio Avaliação } \\
\text { (em metros) }\end{array}$ \\
\hline Média & 0,30 & 0,27 \\
\hline Desvio Padrão & 0,10 & 0,09 \\
\hline Mínimo & 0,11 & 0,09 \\
\hline Máximo & 0,98 & 0,90
\end{tabular}

O conjunto de folhas foi analisado também segundo o ordenamento crescente dos erros a fim de se determinar o erro máximo em $90 \%$ das folhas. Esta forma de analisar traz um paralelo com o que é proposto no PEC, pontuando uma tolerância específica neste percentual das unidades testadas, somando-se a isso o valor do desvio padrão, que garante que os $10 \%$ acima deste limiar não se afastem muito deste valor. Foi observado que em $90 \%$ das 645 folhas o Erro Médio chegou a 0,41m no Georreferenciamento e a 0,37m na Validação.

Considerando o Erro Médio em 90\% das folhas e o Desvio Padrão, poderíamos dizer, neste paralelo com o proposto no $\mathrm{PEC} / \mathrm{PCD}$, que o conjunto dos dados poderiam ser classificados como na classe A no PEC, classe B no PEC/PCD e na classe 1 no Padrão SPU para a escala 1:1.000, já que o Erro Médio em 90\% das unidades testadas ficou abaixo de 0,5m e o Desvio Padrão foi de 0,28 e 0,26m para o Georreferenciamento e Avaliação.

Como esses dados se encontravam associados às escalas 1:1.000 e 1:2.000 (estas últimas se referindo ao município do Rio de Janeiro), optou-se por fazer a análise em separado para cada um destes subconjuntos. 
A Tabela 3 apresenta os valores observados para as 606 folhas na escala 1:1.000, envolvendo os demais municípios do estado do Rio de Janeiro.

Tabela 3: Valores de média, desvio padrão, valores mínimo e máximo observados para os Erros Médios do georreferenciamento e da avaliação das folhas TIPO 1, do estado do Rio de Janeiro, exceto para a capital.

\begin{tabular}{l|c|c} 
Estatística & $\begin{array}{c}\text { Erro Médio } \\
\text { Georreferenciamento } \\
\text { (em metros) }\end{array}$ & $\begin{array}{c}\text { Erro Médio Avaliação } \\
\text { (em metros) }\end{array}$ \\
\hline Média & 0,28 & 0,26 \\
\hline Desvio Padrão & 0,07 & 0,07 \\
\hline Mínimo & 0,11 & 0,09 \\
\hline Máximo & 0,65 & 0,66
\end{tabular}

Como pode-se observar na Tabela 3 os valores encontrados são ainda mais baixos que os obtidos na análise referente ao conjunto total, com o maior Erro Médio ficando abaixo de 0,7 metro. O Erro Médio do Georreferenciamento em 90\% das folhas foi de até 0,36 metro e na Avaliação de até 0,32 metro, com desvio padrão de 0,07 metro tanto para o Georreferenciamento, quanto para a Avaliação. Seguindo o paralelo com o PEC ou PEC/PCD pode-se inferir que as folhas apresentam valores compatíveis com o especificado para a escala 1:1.000 classe A do PEC, classe B do PEC/PCD e classe 1 do Padrão SPU (de acordo com o apresentado na Tabela 1).

Analisando o subconjunto das folhas referentes ao município do Rio de Janeiro, todas na escala 1:2.000, tem-se um total de 39 folhas onde foi observada uma média dos Erros Médios de 0,53 metro com Erro Médio Máximo de 0,98, conforme é apresentado na Tabela 4.

Tabela 4: Valores de média, desvio padrão, mínimo e máximo Erro Médio para o georreferenciamento e para a avaliação das folhas TIPO 1 do município do Rio de Janeiro.

\begin{tabular}{l|c|c} 
Estatística & $\begin{array}{c}\text { Erro Médio } \\
\text { Georreferenciamento } \\
\text { (em metros) }\end{array}$ & Erro Médio Avaliação \\
\hline
\end{tabular}




\begin{tabular}{l|c|c} 
& & (em metros) \\
\hline Média & 0,53 & 0,45 \\
\hline Desvio Padrão & 0,16 & 0,15 \\
\hline Mínimo & 0,24 & 0,23 \\
\hline Máximo & 0,98 & 0,90
\end{tabular}

O Erro Médio em $90 \%$ das folhas foi de 0,70 metro para o Georreferenciamento e de 0,66 para a Validação, com desvio padrão de 0,16 e 0,15 metro, respectivamente. Esses valores indicam, em um paralelo com o PEC, que as folhas se mantêm compatíveis com o especificado para a escala 1:2.000, classe A do PEC, classe B do PEC/PCD e classe 1 do Padrão SPU.

Considerando a data de confecção das folhas (muitas com mais de 60 anos) e do fato da digitalização ter sido feita com as folhas em papel (que normalmente apresentam algum grau de deformação em função das condições de armazenamento, dobramentos, umidade etc.), também se chega à conclusão de que os resultados foram melhores do que o esperado. Além disso, em média, os Erros Médios da Avaliação ficaram menores do que os do Georreferenciamento, o que gerou uma certa surpresa. Em função disso, optou-se por fazer, de forma amostral, uma nova avaliação em um conjunto reduzido de 10 folhas dos TIPOS 1 e 2 no município do Rio de Janeiro.

Nas folhas do TIPO 1 não foram encontradas diferenças significativas, conforme o apresentado na Tabela 5.

Tabela 5: Resíduos encontrados na análise amostral das folhas TIPO 1 do município do Rio de Janeiro, escala 1:2.000, tendo como base de referência a cartografia vetorial da prefeitura.

\begin{tabular}{l|c}
\multicolumn{1}{c|}{ Estatística } & $\begin{array}{c}\text { RMSE } \\
\text { (em metros) }\end{array}$ \\
\hline Média & 0,23 \\
\hline Desvio Padrão & 0,19 \\
\hline
\end{tabular}




\begin{tabular}{l|c}
\hline Mínimo & 0,06 \\
\hline Máximo & 0,54
\end{tabular}

Ao invés de usar o Erro Médio como estimador de erro, calculou-se o RMSE, numa tentativa de se ter uma análise mais crítica dos dados. Pela análise da Tabela 5, percebe-se que a média dos RMSE foi ainda mais baixa do que a dos Erros Médios do conjunto total. $\mathrm{O}$ mesmo aconteceu com o Desvio Padrão e os Valores Mínimo e Máximo de RMSE. Analisando o deslocamento em cada ponto encontrou-se apenas 2 pontos entre os 100 testados que apresentaram valor maior do que 1 metro (com 1,09 e 1,12 metros). O RMSE em $90 \%$ das folhas foi de até 0,33 metro, com desvio padrão de 0,19 metro. Fazendo o mesmo paralelo com o PEC, pode-se dizer que para essa amostra os valores de RMSE foram compatíveis com o especificado para a escala 1:2.000, classe A, do PEC/PCD. Como esta classe indica mais exatidão do que a classe $\mathrm{A}$ do $\mathrm{PEC}$, não cabe uma classificação com relação ao PEC para esta escala. Desta forma as folhas desta amostra estão apresentando exatidões compatíveis com a classe A da escala 1:1.000 do PEC. Isso vale para o Padrão proposto para a SPU: estas amostras apresentam erros médios que indicam exatidão compatível com a classe 1 deste padrão. Ou seja, o resultado encontrado na avaliação amostral foi considerado ainda melhor do que o observado na avaliação feita para todo o conjunto das 39 folhas do município.

Como mencionado anteriormente, para as folhas do TIPO 2 foram priorizadas coleções localizadas apenas no município do Rio de Janeiro. As 69 folhas georreferenciadas, nas escalas 1:500 e 1:1.000, foram analisadas segundo a mesma lógica, considerando todo o conjunto e apenas 10 folhas amostrais. Uma síntese dos resultados é apresentada na Tabela 6.

Tabela 6: Média, desvio padrão, valores mínimo e máximo dos Erros Médios das 69 folhas 1:500 e 1:1.000 do TIPO 2 do município do Rio de Janeiro.

\begin{tabular}{l|c|c} 
Estatística & $\begin{array}{c}\text { Erro Médio } \\
\text { Georreferenciamento } \\
\text { (em metros) }\end{array}$ & $\begin{array}{c}\text { Erro Médio Avaliação } \\
\text { (em metros) }\end{array}$ \\
\hline Média & 1,29 & 1,09 \\
\hline Desvio Padrão & 0,96 & 0,81 \\
\hline
\end{tabular}




\begin{tabular}{l|c|c}
\hline Mínimo & 0,04 & 0,03 \\
\hline Máximo & 4,82 & 3,50
\end{tabular}

A média dos Erros Médios encontrada foi de 1,30m, com Desvio Padrão de 1,00m para o Georreferenciamento, e de $1,12 \mathrm{~m}$ com Desvio Padrão de $0,82 \mathrm{~m}$ para a Avaliação. $\mathrm{O}$ maior Erro Médio encontrado, conforme o esperado, foi para esse grupo de folhas, com 4,82m para o Georreferenciamento e 3,50m para a Avaliação. O maior Erro Médio em $90 \%$ foi de 2,56m para o Georreferenciamento e $2,17 \mathrm{~m}$ para a Avaliação. Esses valores são parecidos com os observados na avaliação do conjunto total.

Pela análise da Tabela 6, observou-se que a média dos Erros Médios do Georreferenciamento das 69 folhas TIPO 2 ficou em 1,29m, enquanto a média dos Erros Médios da Avaliação foi de 1,09m, com valores de Desvio Padrão de 0,96m e 0,81m, respectivamente. O Erro Médio máximo encontrado foi de 4,82m no Georreferenciamento e de 3,50m na validação. Esses dados foram igualmente organizados para se obter o maior Erro Médio em 90\% das folhas. Foram obtidos valores de 2,56m no Erro Médio do Georreferenciamento e 2,34m no Erro da Avaliação, no limiar de 90\% (para um total de 62 folhas). Estes resultados indicam que estas folhas não apresentam valores de exatidão compatíveis com suas escalas de origem de acordo com o previsto no PEC. Os valores observados indicam que essas folhas apresentam exatidão compatível com a escala 1:5.000, classes B no PEC, classe C no PEC/PCD. Considerando o Padrão SPU proposto, essas folhas teriam exatidões compatíveis com a escala 1:1.000, classe 5 .

Analisando as escalas em separado vemos que não há muita diferença nos valores encontrados. A Tabela 7 mostra os resultados para as 58 folhas 1:500 do TIPO 2.

Tabela 7: Valores de média, desvio padrão, valores mínimo e máximo para os Erros Médios de 58 folhas TIPO 2 na escala 1:500.

\begin{tabular}{l|c|c} 
Estatística & $\begin{array}{c}\text { Erro Médio } \\
\text { Georreferenciamento } \\
\text { (em metros) }\end{array}$ & $\begin{array}{c}\text { Erro Médio Avaliação } \\
\text { (em metros) }\end{array}$ \\
\hline Média & 1,30 & 1,12 \\
\hline Desvio Padrão & 1,00 & 0,82 \\
\hline
\end{tabular}




\begin{tabular}{l|c|c}
\hline Mínimo & 0,04 & 0,03 \\
\hline Máximo & 4,82 & 3,50
\end{tabular}

Pela Tabela 7, observa-se que a média dos Erros Médios das 58 folhas 1:500 (1,30m e $1,12 \mathrm{~m}$ para o Erro do Georreferenciamento e da Avaliação, respectivamente) ficou muito próxima da obtida para o conjunto completo de folhas TIPO $2(1,29 \mathrm{~m}$ e 1,09m). Os valores de Desvio Padrão, Erros Mínimo e Máximo também apresentaram diferenças pequenas. O Erro Médio máximo em $90 \%$ das folhas foi de 2,56m e 2,17m para os Erros Médios do Georreferenciamento e da Avaliação, respectivamente. Novamente esses valores estão muito próximos ou idênticos aos observados no conjunto total de 69 folhas TIPO 2. Adotando-se a mesma análise comparativa com o proposto no PEC, estas folhas repetem o resultado e apresentam exatidão compatível com o especificado para a escala 1:5.000, classes B no PEC e classe $\mathrm{C}$ no PEC/PCD. Considerando o Padrão SPU essas folhas estariam classificadas na escala 1:1.000, classe 5 .

Em uma análise separada das 11 folhas 1:1.000 do TIPO 2, também não se observa uma mudança significativa nos valores de Média e Desvio Padrão dos Erros Médios, conforme o apresentado na Tabela 8. Os Valores Máximos encontrados, no entanto, apresentam diferenças maiores, tanto para o Georreferenciamento quanto para a Avaliação, quando comparados com a escala 1:500. O Erro Médio em 90\% das folhas não passou de $2,13 \mathrm{~m}$ e $2,34 \mathrm{~m}$ para o Georreferenciamento e para a Avaliação, respectivamente. Com estes valores, as folhas 1:1.000 apresentam exatidão compatível com o especificado para a escala 1:5.000, classes A no PEC e classe B no PEC/PCD. No Padrão SPU essas folhas apresentam exatidões compatíveis com a escala 1:1.000, classe 5 .

Tabela 8: Valores de média, desvio padrão mínimos e máximos dos Erros Médios das 11 folhas 1:1.000 do TIPO 2 do município do Rio de Janeiro.

\begin{tabular}{l|c|c} 
Estatística & $\begin{array}{c}\text { Erro Médio } \\
\text { Georreferenciamento (em } \\
\text { metros) }\end{array}$ & $\begin{array}{c}\text { Erro Médio Avaliação } \\
\text { (em metros) }\end{array}$ \\
\hline Média & 1,24 & 0,94 \\
\hline Desvio Padrão & 0,73 & 0,75 \\
\hline
\end{tabular}




\begin{tabular}{l|c|c}
\hline Mínimo & 0,39 & 0,22 \\
\hline Máximo & 2,22 & 2,66
\end{tabular}

Os valores observados nas folhas do TIPO 2 são bem mais altos do que os observados nas folhas do TIPO 1, mas, ainda assim, abaixo do esperado, dado as condições originais. $\mathrm{O}$ fato dos valores observados ao separar as folhas de acordo com a escala não serem muito diferentes, sugere que a escala tem um papel secundário na influência do Erro Médio. As maiores diferenças encontradas em relação ao TIPO 1 referem-se à dificuldade de se encontrar feições bem identificáveis na base antiga convertida e nas ortofotos atuais, em geral pela desatualização das primeiras, mas também pelo problema relativo à paralaxe, que dificulta (ou até impossibilita, em alguns casos) a identificação de pontos no terreno. Outro problema observado refere-se ao fato de que, em algumas folhas, só se encontram opções no entorno imediato da LTM, embora o ideal fosse selecionar pontos mais bem distribuídos por toda a folha (como o processo realizado nas folhas do TIPO 1).

Além dos valores de Erros Médios se encontrarem ainda um pouco abaixo do esperado, novamente observou-se que, em média, os Erros Médios da Avaliação ficaram menores do que os do Georreferenciamento (exceto quando a análise focou os $90 \%$ das folhas da escala 1:1.000). Assim, foi feita uma nova avaliação, desta vez considerando apenas uma amostragem de 10 folhas (7 na escala 1:500 e 3 folhas 1:1.000). Da mesma forma que o realizado para as folhas TIPO 1. Nesta abordagem, ao invés de se simular um novo Georreferenciamento, foi feita a plotagem dos pontos e extraídas suas coordenadas, calculando-se o deslocamento final entre o ponto identificado na base convertida e na base cartográfica atual. A Tabela 9 mostra a síntese dos resultados obtidos.

Tabela 9: Média, desvio padrão, valores mínimo e máximo para o RMSE na nova validação, considerando a amostra de 10 folhas.

\begin{tabular}{l|c}
\multicolumn{1}{c|}{ Estatística } & $\begin{array}{c}\text { RMSE } \\
\text { (em metros) }\end{array}$ \\
\hline Média & 2,52 \\
\hline Desvio Padrão & 1,13 \\
\hline Mínimo & 0,25 \\
\hline
\end{tabular}


Considerando a Tabela 9 é possível ver que os valores encontrados foram diferentes e até mais altos do que na Avaliação feita usando a simulação de Georreferenciamento com as ortofotos como referência. Ressalta-se que os valores de RMSE se aproximaram do esperado, com 2,52m de Média e 1,13m de Desvio padrão, além de um RMSE máximo de 5,93m. O RMSE em $90 \%$ das folhas (9 de um total de 10) não passou de 3,46m. Ao fazer o paralelo com o PEC, as amostras das folhas TIPO 2 manteriam a exatidão compatível com o especificado para a escala 1:5.000, classes B no PEC e classe C no PEC/PCD. No Padrão SPU essas folhas apresentam exatidões compatíveis com a escala 1:1.000, classe 5.

Para finalizar, uma análise preliminar do comportamento de uma pequena amostra das folhas do TIPO 3 (em um total de 10) mostrou que metade apresentou erros pequenos, ainda menores do que a maioria das folhas do TIPO 2. Porém, das 5 folhas restantes, duas apresentaram resultados muito ruins, com erros ultrapassando 20 metros. As outras três folhas não apresentavam o mínimo de 4 pontos identificáveis nas bases de referência, não permitindo seu georreferenciamento. Em função disso, considerou-se que as folhas do TIPO 3 devem ser reavaliadas e, possivelmente, mereçam uma proposta de georreferenciamento diferenciada das do TIPO 2.

Um resumo dos resultados obtidos nas avaliações considerando a tipologia proposta e as escalas de mapeamento, para o estudo de caso do município do Rio de Janeiro, é apresentado na Tabela 10.

Tabela 10: Quadro resumo das avaliações obtidas para a cartografia do município do Rio de Janeiro

\begin{tabular}{l|c|c}
\multicolumn{1}{c|}{ Escala/Tipo } & TIPO 1 & TIPO 2 \\
\hline $\mathbf{1 : 5 0 0}$ & & \\
$P E C$ & & $1: 5.000$, classe B \\
$P E C-P C D$ & & $1: 5.000$, classe C \\
$S P U$ & & $1: 1.000$, classe 5 \\
\hline
\end{tabular}




\begin{tabular}{l|l|l}
\hline $\mathbf{1 : 1 . 0 0 0}$ & & \\
$P E C$ & & $1: 5.000$, classe A \\
$P E C-P C D$ & $1: 5.000$, classe B \\
$S P U$ & $1: 1.000$, classe 5 \\
\hline $\mathbf{1 : 2 . 0 0 0}$ & $1: 2.000$, classe A & \\
$P E C$ & $1: 2.000$, classe B & \\
$P E C-P C D$ & $1: 2.000$, classe 1 & \\
$S P U$ & &
\end{tabular}

A figura 15 apresenta uma amostra da correlação entre os dois conjuntos de dados, o antigo e o novo, em que é possível perceber que a correlação espacial é forte, viabilizando operações futuras para integração e atualização desta base cartográfica.

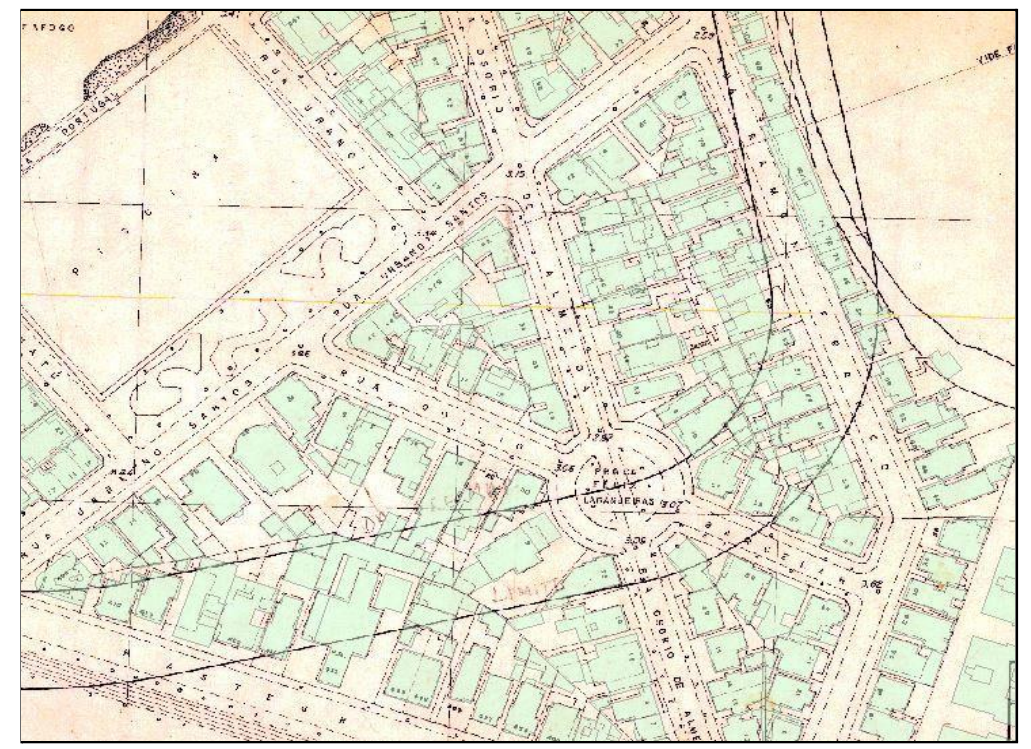

Figura 15: Detalhe da folha 527-T, classificada como do TIPO 2, escala 1:1.000, integrada com a cartografia atual do IPP (em verde).

\section{CONSIDERAÇÕES FINAIS}

O processo de georreferenciamento das folhas digitalizadas da base antiga se encontra em andamento e ainda há muito trabalho a ser feito: avaliações continuadas para os TIPOS 2 e 
3, com desenvolvimento de metodologia ajustada para o TIPO 3 e possíveis ajustes para o TIPO 2.

Para o TIPO 1 considera-se que a proposta metodológica está praticamente concluída e os resultados obtidos foram bastante satisfatórios, indicando que não houve perda significativa na exatidão das folhas ao passar pelos procedimentos de digitalização e georreferenciamento. Os resultados obtidos para as 39 folhas do município do Rio de Janeiro (escala 1:2.000) não foram considerados muito diferentes dos obtidos para as demais 606 folhas referentes ao restante do estado. Apesar deste trabalho focar no município, optou-se por apresentar os resultados de todo o estado para a cartografia do TIPO 1 de modo a mostrar a estabilidade dos mesmos, reforçando a robustez do método proposto. Toda as avaliações realizadas indicaram que os erros foram menores do que o especificado para as escalas originais $(1: 1.000$ e 1:2.000).

Com relação à cartografia categorizada como TIPO 2, por suas características complexas, foi detectada uma perda de exatidão significativa, embora dentro do esperado, já que o georreferenciamento teve que ser feito de uma forma totalmente adaptada às poucas informações e feições existentes.

Apesar dos resultados mostrarem um erro externo maior do que o especificado para a escala original do produto (considerando a avaliação de todas as folhas e usando a mesma referência cartográfica do georreferenciamento) os valores ultrapassam em 2 metros o limite para a escala 1:500 e 1,1m o limite para a escala 1:1.000), o erro interno ultrapassou menos de $70 \mathrm{~cm}$ no caso das folhas 1:500 e pouco mais de $10 \mathrm{~cm}$ nas folhas 1:1.000). Os erros encontrados foram maiores para as folhas na escala 1:500, indicando que a variação de escala tem menos peso no processo. Provavelmente as condições originais das folhas, incluindo a desatualização, são os principais responsáveis pelos erros encontrados. Observando os resultados da escala 1:2.000, os valores de exatidão ultrapassaram em menos de 60 centímetros a tolerância para a escala. Ao se analisar as 10 folhas selecionadas para a segunda avaliação, reunindo amostras das duas escalas em conjunto, e usando uma referência diferente do georreferenciamento - a base vetorial atual - os erros aumentaram e passaram em 1,5 metro o limite para a escala 1:2.000, embora apresentassem erro interno compatível com esta escala.

A proposta de um índice específico para uma cartografia antiga, com poucas ou nenhuma referência cartográfica, que seja mais tolerante, se justifica pela compreensão das dificuldades de todo este processo e pelo fato apresentado inicialmente de que o resultado da qualidade final do produto não tem como ser superior ao que lhe deu origem.

Reforça-se ainda que o fato de, em todos os casos, o erro interno ser baixo pode ser considerado um indicador de que se tem uma estabilidade no processo e o erro observado deve ser homogêneo na folha como um todo. 
Considerando a importância deste acervo da SPU e as condições dos materiais utilizados, pode-se dizer que, no geral, os resultados são bastante satisfatórios, por permitir a utilização de um material que é considerado única fonte de referência para as linhas LTM e LPM e que, de outra forma, teriam pouca - senão nenhuma - utilidade, uma vez que todos os procedimentos precisam ser feitos no meio digital e de maneira georreferenciada - o que seria impossível para as folhas do TIPO 2 (e, consequentemente, TIPO 3).

Para o caso do TIPO 3 será preciso realizar uma nova avaliação considerando-se suas características de construção, de quantidade e tipo de informação disponíveis para, a partir disso, ser desenvolvida uma metodologia específica.

\section{Notas}

1. Considerando o volume de dados a ser tratado, neste trabalho o foco foi dado à cartografia classificada como do TIPO 1 e TIPO 2.

2. Na verdade este procedimento foi aplicado para a totalidade das folhas do TIPO 1 do estado do Rio de Janeiro (645), mas no âmbito do presente trabalho, cujo recorte espacial é o município, serão priorizadas as folhas de sua cartografia

3. Este procedimento foi testado para um total de 69 folhas do TIPO 2 e 10 folhas do TIPO 3, todas no município do Rio de Janeiro.

4. O PEC (Padrão de Exatidão Cartográfico, estabelecido no Decreto 89.817), de 1984, estabelece que as folhas devem ser classificadas de acordo com o erro observado em $90 \%$ dos pontos testados e com o desvio padrão do erro nesses pontos. Pela velocidade demandada no processo e pela pequena quantidade de pontos disponíveis por folha, optou-se em fazer uma avaliação pelo conjunto de folhas por tipo/escala. A avaliação foi feita segundo o Erro Médio obtido automaticamente através do QGIS. Ainda que não seja exatamente uma avaliação segundo o PEC, tem-se um paralelo com o especificado no PEC por se utilizar o limite de $90 \%$ e estar se considerando o desvio padrão.

\section{REFERÊNCIAS BIBLIOGRÁFICAS}

BRASIL, Decreto $\mathrm{n}^{\circ} 89.817$ de 20 de junho de 1984. Normas Técnicas da Cartografia Nacional. Diário Oficial da União, 20 de junho de 1984. Site: http://www.planalto.gov.br/ccivil_03/decreto/1980-1989/d89817.htm. Acesso em 27/10/2020.

CASTIGLIONE, Luiz Henrique Guimarães. Análise Histórico-Crítica: As Transformações das Geoinformações, In: Epistemologia da Geoinformação: uma análise histórico-crítica. Tese de doutorado UFF/IBICT/PPGCI, 2009, 371pg. 
FIGUEIREDO, Cláudio Chagas. Contribuição para a Análise Urbana a partir do Georreferenciamento de Elementos Morfométricos de Plantas Antigas: Rio de Janeiro, 1812 e 1906. Dissertação de Mestrado UNB, Brasília, 2008, 90pg.

GOMES, Paulo César da Costa. Quadros Geográficos: uma forma de ver, uma forma de pensar. ISBN: 978-85-286-2245-4. Ed Bertrand Brasil Ltda. Rio de Janeiro. 2017, 158pg.

LE GOFF, Jacques. Documento/Monumento, In: História e Memória. Tradução Bernardo Leitão et al 4ed. Campinas, São Paulo. Editora UNICAMP, 1996, p. 535-553.

MENEZES, Paulo Márcio Leal de; FERNANDES, Manoel do Couto. Roteiro de Cartografia. ISBN: 978-85-7975-084-7. Ed. Oficina de Textos, 2013, 288pg.

MINISTÉRIO DO PLANEJAMENTO. Metodologia de Conversão de Dados Geoespaciais da SPU (Capítulo Georreferenciamento), versão 2.1. Secretaria do Patrimônio da União, 2018.

MINISTÉRIO DO PLANEJAMENTO. Secretaria do Patrimônio da União. https://governancadeterras.com.br/wp-content/uploads/2018/03/Secretaria-do-Patrimônio-daUnião-SPU.pdf . 2021.

THIERS, Paulo Roberto Lopes. Localização Geodésica da Linha de Preamar Média com relação ao ano de 1831, na praia do Futuro, Fortaleza-CE, Brasil. Boletim Goiano de Geografia, v.32, n.1, p.31-44, jan/jun, 2012.

\section{COMO CITAR ESTE TRABALHO}

Cruz, C.B. M; Barros, R.S; Coelho, R.C.S; Marques, J.V, J.V F.P.A; Nascimento, L.L; Matos, M.S; Viégas, V.S; Souza, E.M.F.R; Duarte, G.S; Silva, I.A; Viana, J.V.R; Co, J.C.V; Menezes, D.J. \& Sampaio, C.S. O desafio do georreferenciamento de cartas antigas em escala cadastral em apoio a estruturação de uma base de dados geoespaciais - estudo de caso para o município do Rio de Janeiro. Revista Tamoios, São Gonçalo, v. 17, n. 2, p. 158-186, 2021. Disponível em: https://doi.org/10.12957/tamoios.2021.56122. Acesso em: DD MM. AAAA. 